\title{
Plano de carreira e avaliação dos professores: encontros e desencontros
}

\author{
- Janete Palazzo* \\ - Candido Alberto Gomes"*
}

\section{Resumo}

0 objetivo deste estudo foi verificar se os critérios de progressão na carreira de uma instituição de ensino superior são os mesmos que formam um bom docente na perspectiva dos alunos. A literatura destaca vários fatores que interferem no desempenho dos alunos, mas considera que os critérios clássicos de progressão tendem a não exercer claramente efeitos sobre o rendimento dos alunos. A pesquisa exploratória utilizou, como instrumento de coleta de dados, um questionário preenchido pelos alunos, previamente construído, testado e aprovado como parte do processo de avaliação institucional. Além de verificar o desempenho dos docentes na perspectiva dos alunos, relacionaram-se as respostas ao questionário com as caracteristicas docentes valorizadas pelo Plano de Carreira (titulação, experiência, tempo de serviço e publicações científicas). Concluiu-se que, na instituição estudada, não houve relação significativa entre a avaliação dos docentes e as variáveis para progressão na carreira, confirmando a literatura sobre a educação básica.

Palavras-chave: Educação superior. Carreira do magistério. Economia da educação. Avaliação de professores. Avaliação institucional.

\section{Professors' career and evaluation: matches and mismatches Abstract}

This study aimed to assess if the criteria for progressing in the professors' career of a higher education institution are the same that make a teacher good in the pupils' view. The literature highlights many factors that influence pupils' gains, however, it considers that the classic progressing criteria tend not to wield clearly effects on pupils' gains. The exploratory research project used, to collect data, a questionnaire filled out by students, previously constructed, tested and approved as part of the institutional evaluation process. Besides

\footnotetext{
* Mestre em Educação, Universidade Católica de Brasilia, UCB; Professora da Faculdade de Ciências Sociais e Tecnológicas (FACITEC). E-mail:janete@facitec.br.

* Doutor em Educação, Universidade da Califórnia, Los Angeles; Titular da Cátedra UNESCO de Juventude, Educação e Sociedade, UCB.E-mail: clgomes@terra.com.br.
} 
verifying the professors' performance from the students' perspective, this research project related professors' characteristics valued by the career ladder (degree, experience, seniority in the institution and academic publications) to their performance according to the students' evaluations. It was concluded that, in the institution investigated, there was no significant relationship between the evaluation of professors' performance and the variables for progressing in career, confirming the literature on basic education.

Keywords: Higher education. Teaching career. Education Economy. Teachers' evaluation. Institutional evaluation.

\section{Carrera docente y evaluación: encuentros y oposiciones Resumen}

El objetivo de esta investigación es el de verificar si los criterios de progresión en la carrera docente de una institución de educación superior son los mismos valorados por la evaluación de los estudiantes. La literatura destaca varios factores que afectan el rendimiento de los estudiantes, pero concluye en general que los criterios adoptados en las carreras no tienen efectos claros sobre el rendimiento discente. Esta investigación exploratoria utilizó un cuestionario de evaluación de los docentes por los estudiantes, que había sido previamente construido, testado y aprobado en la evaluación institucional. Se relacionaran los resultados de la evaluación por los estudiantes a las características de los profesores destacadas por la carrera (nivel de escolaridad, tiempo de trabajo y publicaciones cientificas). Se concluye que, en este caso, no hubo relación significativa entre la evaluación del desempeño de los profesores y las variables enfatizadas por la carrera, confirmando así la literatura acerca de la educación básica.

Palabras clave: Educación superior. Carrera docente. Economía de la educación. Evaluación de profesores. Evaluación institucional.

Há várias décadas, sistemas educacionais e redes escolares têm buscado alternativas para aperfeiçoar e incentivar o desempenho dos professores. Entre as alternativas até agora utilizadas, temos os planos de carreira baseados nos resultados do trabalho docente, o pagamento pelo mérito (individualmente e/ou em grupo) e diversas formas de avaliação dos profissionais, tanto para serem admitidos como para progredirem na carreira, tais como provas e exames, avaliação pelos pares, superiores e alunos e outros processos. Essas mudanças pretendem sair dos lugares comuns das carreiras burocráticas, em que todos recebem os mesmos salários se atendem a certos requisitos, em especial os diplomas e certificados e o tempo de serviço. Tais critérios são universalistas, permitem tratamento igualitário e buscam recompensar o serviço público pelo mérito, o que corresponde fielmente às defini- 
ções de burocracia. Na educação superior, as práticas já apresentam certa tradição e, em certos casos, encontram-se sistemas educacionais em que os docentes desse nível são continuamente avaliados, inclusive pela sua produção intelectual, mas, na educação básica, se encontram fortes resistências para implantar a avaliação e aproximar as recompensas e estímulos da qualidade do desempenho docente. Entre outros motivos, está a complexidade da gestão de pessoal em redes escolares que podem espalhar-se por todo um pais.

Esta pesquisa exploratória busca verificar, no caso de uma instituição de educação superior isolada e particular, os encontros e desencontros entre 1) o plano de carreira (altamente valorizado pela avaliação governamental) e a literatura a respeito do trabalho docente; e, 2) o plano de carreira e as avaliações dos alunos, que se encontram na ponta, isto é, na sala de aula. Será o plano de carreira coerente com a situação atual da pesquisa, isto é, os incentivos para progredir são aqueles que a literatura considera os melhores e mais seguros preditores do aproveitamento do aluno? Por outro lado, os discentes avaliam melhor os seus professores que se encontram em status mais alto no plano de carreira e, inversamente, avaliam de maneira menos positiva aqueles que se acham em status mais baixo? Se o dinheiro público ou privado é utilizado para incentivar e recompensar o mérito, conforme os princípios da racionalidade burocrática é legítimo esperar que esses recursos sejam alocados de tal modo a assegurar o adequado retorno aos indivíduos e à coletividade. Isso, porém, acontece? Como costuma ocorrer em pesquisas exploratórias, geraram-se intrigantes perguntas, que servem à reflexão e a futuras pesquisas, e poucas respostas prontas.

\section{Incentivos e desempenho: de braços dados?}

Diferentes são as formas de incentivar um profissional pelo trabalho que ele desenvolve. Muitos pensam que incentivos envolvem apenas questões salariais e financeiras. Entretanto, existem várias outras formas de incentivo, tais como infraestrutura física adequada do local de trabalho, bens materiais de uso diário, oportunidades de crescimento profissional, estabilidade trabalhista, diferenciação salarial, reconhecimento e prestígio, além de outros benefícios extrassalariais (VEGAS; UMANSKY, 2005a). No caso dos profissionais do magistério, este contexto não é diferente. A valorização do professor é um processo indispensável, considerada a importância da profissão.

Uma vez que os docentes respondem bem aos incentivos que Ihes são concedidos, a qualidade do processo ensino-aprendizagem pode ser melhorada com a criação de estímulos para atrair e manter os docentes qualificados e motivados. Nesse sentido, Tachizawa e Andrade (2006) defendem que a principal finalidade do plano de carreira é ajudar no aprimoramento da organização, por meio de melhor aproveitamento do pessoal, promovendo o desenvolvimento e a autorrrealização dos atores envolvidos. 
No Brasil, é mais comum encontrar planos de carreira do magistério cujos critérios são a titulação, a experiência docente e a existência de publicações no currículo do professor. Tais critérios são recorrentes devido à sua relevância para a avaliação de cursos pelo Ministério da Educação (MEC). Ou seja, professores bem titulados, experientes e com numerosas publicações elevam o conceito do curso avaliado, supostamente porque tais professores têm mais alto desempenho.

Entretanto, existem pesquisas que comprovam a ausência de relação entre os critérios mais valorizados pelos planos de carreira com o rendimento dos alunos (GOLDHABER; BREWER, 1996; CASASSUS, 2002; WAYNE; YOUNGS, 2003; MELLO E SOUZA, 2005; GOMES, 2005; HANUSHEK; RIVKIN, 2006; HANUSHEK, 2006). Ora, se a função da escola é oferecer aos estudantes oportunidades de aquisição de competência cognitiva (SOARES, 2005), cujo mediador é o professor, os planos de carreira deveriam, então, estar fundamentados em critérios que apresentassem influência sobre o rendimento dos alunos. Por isso mesmo, Zabalza (2004) considera que tais planos devem estar associados a méritos profissionais, pois, nos casos em que a mudança de categoria está vinculada ao alcance de critérios burocráticos, tais como antiguidade, há menor probabilidade de que o professor seja motivado e estimulado para o desenvolvimento de suas atividades.

Casassus (2002), a partir dos resultados de sua pesquisa, defende que é preciso rever o peso atribuído à antiguidade nos sistemas de remuneração docente, uma vez que este critério não interfere no rendimento dos alunos. Mello e Souza (2005) corrobora essa idéia, ao afirmar que os maiores salários estão associados ao longo tempo de experiência, bem como à titulação do professor, fatores identificados em sua pesquisa como irrelevantes para o desempenho dos estudantes. 0 autor sugere a introdução de incentivos no sistema de remuneração docente, a fim de melhorar os resultados dos alunos.

Vegas e Umansky (2005b) afirmam que as politicas de carreira docente deveriam incluir: salários adequados (tão altos quanto os oferecidos a pessoas com características semelhantes em outras profissões), salários maiores para docentes com melhor desempenho, salários maiores para os professores que trabalham em condições mais difíceis (tais como em áreas rurais ou para população desfavorecida), carreira docente bem definida, com oportunidade de promoção e reconhecimento público e prestígio para professores de excelência.

Figlio e Kenny (2007), ao analisarem dados longitudinais de larga escala, encontraram relação positiva entre 0 uso de incentivos individuais para professores e 0 desempenho dos alunos. Os autores ressaltam que duas são as interpretações possiveis para esta conclusão. A primeira é que os incentivos exigem mais esforço dos docentes, resultando em maior nota em testes padronizados. A segunda é que as escolas mais efetivas tendem a adotar incentivos individuais para professores, o que 
tornaria o resultado falso. Desse modo, não se sabe se a relação positiva encontrada entre os incentivos individuais para os docentes e o desempenho dos alunos é de fato devido ao uso de incentivos ou à não observada qualidade da escola.

\section{Influência das características docentes sobre o rendimento estudantil}

A literatura sobre as características do professor que apresentam impacto sobre 0 rendimento dos alunos no âmbito da educação básica é extensa. Entretanto, em relação à educação superior, as pesquisas são praticamente inexistentes. Mesmo nas pesquisas identificadas, não há unanimidade na academia quanto aos efeitos das caracteristicas docentes sobre o desempenho acadêmico. Hoffmann e Oreopoulos (2006) foram alguns dos poucos que se preocuparam em estudar a relação entre as características docentes e o desempenho acadêmico no ensino pós-médio. Os autores utilizaram uma série de dados de estudantes de uma grande universidade canadense e seus respectivos instrutores no periodo de 1996 a 2005. A qualidade do docente foi medida de forma objetiva, subjetiva e pelo valor agregado. As estimativas foram realizadas conforme a variação entre as diferentes seções dentro do mesmo curso. Além disso, foram controladas as variáveis do dia da semana e do período do dia em que as aulas foram ministradas e também do primeiro ano do curso.

Os autores concluíram que o fato de o docente trabalhar em regime parcial ou integral, fazer pesquisa, ter o direito de estabilidade no emprego (tenure) ou alto salário não apresenta impactos expressivos sobre o rendimento dos alunos. Ademais, discentes cujos professores tendem a receber boa avaliação apresentam menor probabilidade de cancelar um curso, maior probabilidade de receber notas altas e maior possibilidade de matricular-se em cursos semelhantes nos anos posteriores. Outra conclusão é que pode haver um grande impacto cumulativo sobre alunos de segundo e terceiro anos quando submetidos a docentes eficazes ou ineficazes a cada ano. Esse impacto é maior sobre os alunos com rendimento mais baixo no ensino médio. Os autores declaram que a influência do professor sobre o rendimento dos alunos universitários é menor que a influência dos docentes sobre alunos de nível fundamental e médio.

Mello e Souza (2005) realizou uma pesquisa em três escolas municipais do Rio de Janeiro a fim de verificar que fatores escolares influenciam o desempenho dos alunos. Nas variáveis relativas ao professor, ele concluiu que a escolaridade do professor tem efeito negativo, tanto no que tange ao número de anos de escolaridade, quanto na separação entre os professores com e sem formação superior. Além disso, identificou que cursos de formação continuada, apenas quando oferecidos pela Secretaria Municipal de Educação, apontam para melhor rendimento estudantil. Além disso, verificou a existência de relação negativa entre o tempo de experiência docente e a aprendizagem dos alunos. 
Por seu lado, Albernaz, Ferreira e Franco (2002) desenvolveram uma pesquisa com base em resultados do Sistema de Avaliação da Educação Básica (SAEB) e descobriram que, quanto mais alto o nível de escolaridade do professor, maior o desempenho dos seus alunos, de forma crescente, conforme o nivel socioeconômico destes. Aferiram, ainda, que o salário do professor tem impacto semeIhante ao nivel de escolaridade do docente. Ou seja, quanto maior o salário do professor, maior o desempenho médio dos alunos. Por outro lado, comprovaram que a experiência docente não apresenta efeitos significativos sobre a aprendizagem dos alunos.

Na América Latina, Casassus (2002) pesquisou o efeito das características dos professores sobre o rendimento dos alunos. Concluiu que a formação pós-média dos docentes apresenta efeito positivo sobre a aprendizagem dos estudantes. Os alunos apresentam ganhos em rendimento a cada ano de formação pós-média do professor. Sobre a capacitação docente, foi observado que Brasil, Paraguai e Cuba apresentaram efeito positivo, principalmente quando integrada com a formação inicial. No que se refere à experiência docente, o autor identificou, em seu estudo, que esta variável não exerce influência sobre o aproveitamento dos alunos. Concluiu que, na América Latina, a relação é ligeiramente negativa para Linguagem e ligeiramente positiva para Matemática.

Quanto ao aspecto da experiência, Croninger e colaboradores (2007) verificaram que alunos ensinados por professores iniciantes (até dois anos de experiência) têm rendimento menor que os submetidos a professores mais experientes. Entretanto, o período mais eficaz parece estar entre dois e cinco anos de experiência. Estes resultados são confirmados por Rivkin, Hanushek e Kain (2005), os quais afirmam que, geralmente, professores em seu primeiro e segundo anos de experiência tendem a apresentar desempenho pior em sala de aula. Tais conclusões são divergentes das encontradas anteriormente por Hanushek e colaboradores (2005), que, utilizando uma estimativa metodológica diferenciada, aferiram que a aprendizagem mais significativa dos alunos se dá quando estes são submetidos a docentes em seu primeiro ano de experiência. Os autores afirmam que o impacto da experiência sobre o desempenho estudantil rapidamente desaparece após o primeiro ano de docência. Eles explicam que a falta de clareza na definição da relação entre resultados e experiência provavelmente contribuíram para que não encontrassem um elo sistemático entre a qualidade da instrução e a experiência. Identificaram, ainda, que titulações e certificações avançadas parecem não ter relação com o rendimento dos alunos. Rivkin, Hanushek e Kain (2005) formularam conclusões semelhantes. Em seu estudo, inferiram que o professor, em seu primeiro ano de experiência docente, aumenta consideravelmente o rendimento dos alunos. Segundo os autores, esse ganho diminui pelos anos seguintes da carreira e, após o terceiro ano de experiência, há poucos indícios de melhoria na produtividade dos alunos. 
Schacter e Thum (2004) concluíram, a partir de pesquisa bibliográfica, que o tempo de experiência do docente tem relação positiva e significante com o rendimento dos estudantes em menos de 30\% das análises. Concluíram, ainda, que estudos de pós-graduação apresentam este efeito em menos de 10\% das pesquisas estudadas. Stronge, Tucker e Hindman (2004) afirmam que não há, na literatura, um consenso a respeito de quantos anos de docência tornam um professor experiente. Entretanto, para fins de eficácia, a variação parece estar entre três e oito anos. Por outro lado, em alguns paises em desenvolvimento, o tempo de experiência docente não tem relação alguma com o desempenho dos alunos (OLIVEIRA; FARRELL, 1993).

Em sintese, titulação, tempo de experiência e salário são as mais estudadas características docentes que apresentam efeito sobre o desempenho escolar dos alunos. Vários autores se empenharam para estudar essas relações. É notório o grande dissenso existente na literatura quanto aos efeitos das características docentes sobre a aprendizagem dos alunos. Por outro lado, os pesquisadores consideram que, dentre as variáveis intraescolares, a qualidade da docência é a mais influente sobre o desempenho dos alunos (NAVARRO, 2002). Os autores que pesquisaram o assunto apresentaram resultados divergentes, uma vez que os efeitos dos fatores sobre 0 desempenho estudantil apareceram positivos, negativos ou neutros.

\section{Metodologia}

A pesquisa, pelas caracteristicas já foram referidas, renuncia a qualquer tipo de generalização, embora as suas conclusões sejam sugestivas ao menos para instituições similares. Os seus resultados podem fundamentar pesquisas mais amplas, com o mesmo ou outro referencial metodológico, valendo-se das limitações deste trabalho e das suas recomendações.

Com a utilização de abordagem quantitativa, relacionaram-se os dados da avaliação dos docentes pelos discentes de uma IES no Distrito Federal com as características dos docentes valorizadas pelo Plano de Carreira da instituição (titulação, tempo de experiência na educação superior, tempo de serviço na instituição e publicação científica).

Os dados relativos às avaliações dos professores referem-se ao ano de 2006, quando a Comissão Própria de Avaliação (CPA) da instituição aplicou questionário idêntico e anônimo nos dois semestres a todos os alunos matriculados, a fim de avaliar o desempenho de todos os professores. 0 instrumento utilizado era composto por 25 itens e algumas questões demográficas, como idade, sexo, curso e realização de outro curso superior. Como padrão de respostas, foi utilizada a escala de Likert com cinco alternativas, de forma a permitir que o respondente pudesse marcar o ponto neutro da escala. 
Os itens do questionário apresentavam afirmações a respeito do professor, as quais o aluno deveria avaliar conforme a sua concordância ou não acerca das sentenças (1- "discordo totalmente", 2- "discordo parcialmente", 3- "nem concordo nem discordo", 4- "concordo parcialmente" e 5- "concordo totalmente"). A partir das respostas dos alunos ao instrumento, cada professor obtém, independente da quantidade de disciplinas que ministra, uma média aritmética que varia de 1 a 5 .

Observa-se que, antes da aplicação dos questionários, foram selecionados aleatoriamente e em momentos distintos, um grupo de alunos representantes de cada curso e um de professores para que, em grupos focais, se fizesse o ajuste dos instrumentos. Na oportunidade, os participantes poderiam sugerir, inclusive, a incorporação de novos itens para o instrumento ou a exclusão de itens já existentes. Quando as alterações foram realizadas, houve a condução de um novo grupo focal pela coordenadora e por um membro da CPA, a fim de validar semanticamente o instrumento.

Uma preocupação da CPA da instituição foi a época do período letivo em que os instrumentos seriam aplicados. 0 calendário acadêmico da instituição estabelece duas semanas de provas ao longo do período letivo. No $1^{\circ}$ semestre de 2006, 0 período de aplicação dos instrumentos foi uma semana anterior à segunda semana de aplicação de provas, enquanto no $2^{\circ}$ semestre os questionários foram respondidos duas semanas antes da segunda semana de provas, a fim de tentar evitar que os alunos fossem contaminados por suas notas no momento de avaliar o professor. A avaliação de docentes pelos alunos na instituição pesquisada é voluntária. Aproximadamente $80 \%$ do total de alunos responderam aos questionários, ou seja, não houve recusa significativa dos respondentes.

Os dados estatísticos foram calculados utilizando-se o banco de dados das duas avaliações docentes, disponibilizados pela instituição, organizados em dois arquivos em Excel. Para a realização das análises estatísticas, foi utilizado o software Statistical Package for the Social Sciences (SPSS), a fim de relacionar as médias de avaliação dos professores e as características dos docentes, no que tange à titulação, ao número de pontos obtido com publicações, ao tempo de experiência docente e ao tempo de dedicação à instituição, segundo o Plano de Carreira da IES.

Foram calculadas medidas de concentração, dispersão e de correlação entre as variáveis. Inicialmente, realizou-se a análise descritiva dos dados. Em seguida, desenvolveu-se a análise fatorial dos resultados. Posteriormente, foi feita a correlação entre os dados da avaliação docente e as características dos professores, a fim de verificar a medida da relação linear entre as variáveis. Depois, realizou-se o teste $t$ de student e a análise de variância (ANOVA), na intenção de verificar a significância estatística das diferenças entre as médias das variáveis. Por fim, foi realizada a regressão múltipla, para analisar a relação entre a média dos docentes na avaliação feita pelos alunos e as variáveis independentes. 


\section{A população}

A população excluiu os professores que ministraram aula em apenas um dos períodos letivos, ou seja, somente fazem parte da pesquisa os professores que lecionaram em todo o ano de 2006, o que resultou em 89 docentes. Na fase de tabulação dos dados, cada professor, independente da quantidade de disciplinas ministradas ou da quantidade de alunos matriculados nelas, ou ainda do período letivo, teve uma única referência de dados, o que fez variar a quantidade de casos por professor de 25 a 499.

Em relação à titulação, os professores estavam distribuidos da seguinte forma: 15 tinham apenas a graduação; 25 eram especialistas; 45 eram mestres e quatro, doutores, como mostra o gráfico 1.

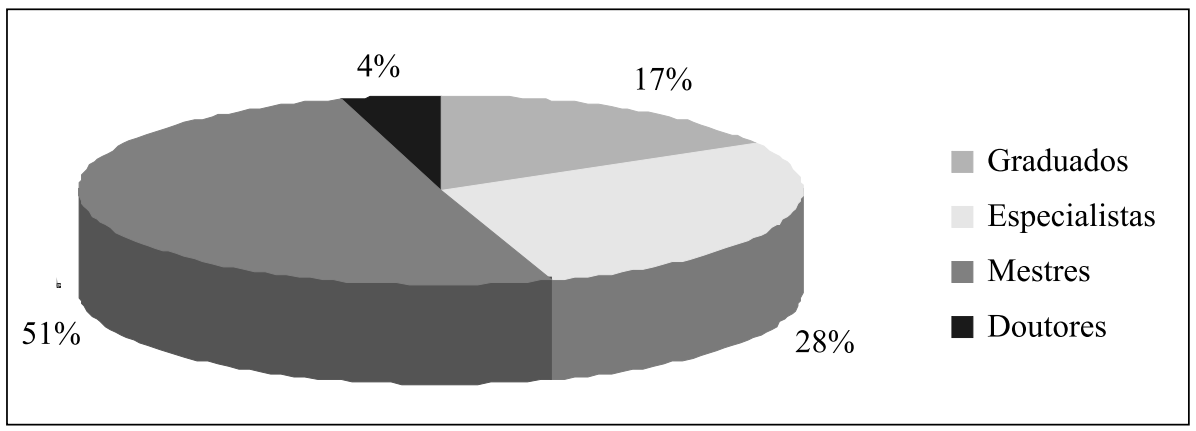

Gráfico 1 - Distribuição dos docentes por titulação - 2006.

Fonte: Secretaria da Instituição (2006).

Quanto ao gênero, 37 dos docentes eram mulheres, representando 41,6\%, e 52 eram homens $(58,4 \%)$. Uma possivel explicação para haver maior quantidade de professores do sexo masculino é a natureza dos cursos oferecidos pela instituição. 0 tempo médio de experiência na educação superior dos professores selecionados para a pesquisa foi de cinco anos e sete meses, com desvio padrão de 3,65. Já o tempo médio de trabalho como docente na instituição foi de dois anos e dois meses, com desvio padrão de 1,28. Isso significa que o corpo docente tem relativamente pouco tempo de trabalho no estabelecimento, inclusive pela autorização recente de determinados cursos.

\section{Características da instituição}

A instituição pesquisada foi credenciada pelo Ministério da Educação no ano de 2001. É uma unidade isolada de educação superior, com fins lucrativos. No ano da pesquisa - 2006 - tinha os seguintes cursos: Administração (habilitação em Marketing e em Análise de Sistemas Gerenciais), Comunicação Social (habilitação em Jorna- 
lismo e em Publicidade e Propaganda), Sistemas de Informação, Direito, Turismo e Pedagogia. No final do ano de 2006, o corpo docente era composto por 116 professores e o discente por 2021 alunos, distribuídos por curso, conforme o gráfico 2.

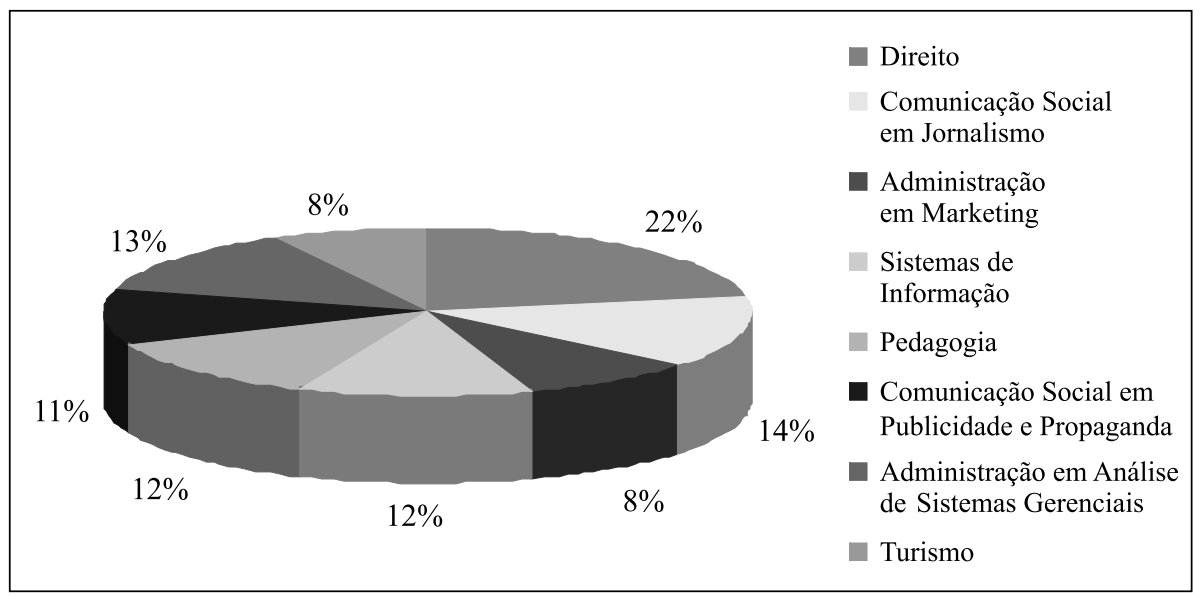

Gráfico 2 - Matrícula da instituição por curso de graduação no $2^{\circ}$ semestre de 2006. Fonte: Secretaria da Instituição (2006).

Destaca-se que os dados do gráfico 2 são referentes ao $2^{\circ}$ semestre de 2006 e que alguns fatores podem interferir no percentual de alunos por curso para que seja maior ou menor. Citam-se, como exemplos, a quantidade de vagas anuais estabelecida pelo MEC, a duração do curso (já que os cursos com maior duração tendem a ter mais alunos), e o quão recente o curso foi autorizado pelo Ministério, de modo que os cursos mais recentes possivelmente terão menor número de matrículas que os cursos que já tenham egressos.

\section{Resultados}

Inicialmente, foram computadas as frequências e as medidas de concentração e de dispersão entre as variáveis. Calculou-se, ainda, o coeficiente de variação para cada item. Essa medida, resultado do quociente da média pelo desvio padrão, indica 0 quanto os dados variam em relação à média. Quanto menor o coeficiente, mais homogêneo é o conjunto de dados. A tabela 1 apresenta a média (quociente da soma dos valores dos elementos pela sua quantidade), o desvio padrão (mede o quanto os elementos se afastam de sua média) e o coeficiente de variação de cada item.

0 primeiro aspecto relevante da tabela 1 é 0 alto valor relativo das médias, tendo em vista que a escala varia de um a cinco. Com exceção do item 11, todos os itens apresentam média superior a quatro. Como limitação da pesquisa, esses resultados devem ser encarados com cautela, especialmente em face do baixo desvio padrão das 
respostas dos alunos, demonstrando alta homogeneidade de respostas. Essa variação pode ser atribuída à seleção dos professores pela instituição, cujos critérios incluem análise curricular, entrevista e aula pública, conforme previsto no Plano de Carreira Docente da faculdade. Igualmente, pode refletir a relação dos alunos com a autoridade pedagógica, ou a "infalibilidade' do 'mestre", nas palavras de Bourdieu e Passeron (1975, p. 124), pois o sujeito tradicionalmente avaliado se torna o avaliador. Este elo assimétrico pode conduzir a uma superestimativa das respostas, tornando expressivas e importantes, do ponto de vista analítico, as pequenas variações entre elas, mensuradas pelo desvio padrão e pelo coeficiente de variação.

Tabela 1 - Média, desvio padrão e coeficiente de variação das respostas dos alunos por item do instrumento de coleta de dados.

\begin{tabular}{l|c|c|c}
\hline Item & Média & $\begin{array}{c}\text { Desvio } \\
\text { Padrão }\end{array}$ & $\begin{array}{c}\text { Coeficiente } \\
\text { de Variação } \\
\text { (\%) }\end{array}$ \\
\hline $\begin{array}{l}\text { 1. Demonstra domínio do conteúdo. } \\
\begin{array}{l}\text { 2. Demonstra clareza na apresentação } \\
\text { dos conteúdos ministrados. }\end{array}\end{array}$ & 4,4002 & 0,9911 & 22,5252 \\
\hline 3. Demonstra organização nos conteúdos ministrados. & 4,2659 & 1,0575 & 24,7904 \\
\hline $\begin{array}{l}\text { 4. Ministra aulas interativas, incentivando } \\
\text { a participação dos alunos. }\end{array}$ & 4,1083 & 1,1710 & 28,5021 \\
\hline $\begin{array}{l}\text { 5. Demonstra ter preparado as aulas. } \\
\text { 6. Relaciona o conteúdo das aulas a } \\
\text { outras áreas do conhecimento. }\end{array}$ & 4,3011 & 1,0593 & 24,6287 \\
\hline $\begin{array}{l}\text { 7. Relaciona o conteúdo das aulas à } \\
\text { realidade do mercado. }\end{array}$ & 4,1514 & 1,0932 & 26,3339 \\
\hline $\begin{array}{l}\text { 8. Estabelece relação entre a teoria e a prática, } \\
\text { respeitadas as especificidades da disciplina. }\end{array}$ & 4,2258 & 1,0572 & 25,0181 \\
\hline $\begin{array}{l}\text { 9. Apresenta o plano de ensino aos alunos } \\
\text { na primeira semana de aula. }\end{array}$ & 4,2235 & 1,1886 & 28,1433 \\
\hline $\begin{array}{l}\text { 10. Cumpre as atividades programadas } \\
\text { no plano de ensino. }\end{array}$ & 4,2598 & 1,0681 & 25,0747 \\
\hline $\begin{array}{l}\text { 11. Utiliza os recursos didáticos } \\
\text { (ex.: dinâmicas de grupo) e tecnológicos } \\
\text { (ex.: data show, retroprojetor) de maneira a } \\
\text { favorecer a compreensão do conteúdo. }\end{array}$ & 3,9376 & 1,3193 & 33,5052 \\
\hline $\begin{array}{l}\text { 12. Incentiva a autonomia, a pesquisa e } \\
\text { o pensar critico dos alunos. }\end{array}$ & 4,5446 & 0,9153 & 20,1400 \\
\hline $\begin{array}{l}\text { 13. Acompanha as atividades do aluno } \\
\text { (tarefas, trabalhos, projetos etc.) }\end{array}$ & 1,1204 & 26,8931 \\
\hline $\begin{array}{l}\text { 14. Mantém comportamento cordial } \\
\text { e respeitoso com os alunos. }\end{array}$ & 1,0789 & 25,4177 \\
\hline
\end{tabular}




\begin{tabular}{|c|c|c|c|}
\hline Item & Média & $\begin{array}{c}\text { Desvio } \\
\text { Padrão }\end{array}$ & $\begin{array}{c}\text { Coeficiente } \\
\text { de Variação } \\
(\%)\end{array}$ \\
\hline 15. Trata os alunos com critério e justiça. & 4,4485 & 0,9726 & 21,8635 \\
\hline 16. Mantém a ordem e a disciplina da turma. & 4,2588 & 1,0517 & 24,6938 \\
\hline 17. Está aberto às críticas e sugestões. & 4,2244 & 1,1314 & 26,7820 \\
\hline 18. Tem disposição para esclarecer dúvidas. & 4,4493 & 0,9856 & 22,1509 \\
\hline $\begin{array}{l}\text { 19. Estabelece estratégias de recuperação } \\
\text { de alunos de menor rendimento. }\end{array}$ & 4,0468 & 1,1681 & 28,8655 \\
\hline $\begin{array}{l}\text { 20. Orienta o sistema de avaliação } \\
\text { (provas, trabalhos etc.) com clareza e precisão. }\end{array}$ & 4,3367 & 1,0191 & 23,4994 \\
\hline $\begin{array}{l}\text { 21. Valoriza a reflexão e o pensar crítico } \\
\text { nos instrumentos de avaliação. }\end{array}$ & 4,2348 & 1,0397 & 24,5517 \\
\hline $\begin{array}{l}\text { 22. Aplica avaliações coerentes } \\
\text { com o conteúdo ministrado. }\end{array}$ & 4,4283 & 0,9745 & 22,0060 \\
\hline $\begin{array}{l}\text { 23. Corrige as avaliações respeitando } \\
\text { critérios previamente estabelecidos. }\end{array}$ & 4,4279 & 0,9680 & 21,8619 \\
\hline $\begin{array}{l}\text { 24. Utiliza outros modos de avaliação que não } \\
\text { sejam única e exclusivamente provas. }\end{array}$ & 4,4189 & 1,0165 & 23,0038 \\
\hline $\begin{array}{l}\text { 25. Faz análise e comentários acerca } \\
\text { dos resultados das avaliações. }\end{array}$ & 4,2785 & 1,0806 & 25,2556 \\
\hline
\end{tabular}

Fonte: Pesquisa de campo (2006).

0 item 11 do instrumento, o qual questiona se o professor utiliza os recursos didáticos (ex.: dinâmicas de grupo) e tecnológicos (ex.: data show, retroprojetor), de maneira a favorecer a compreensão do conteúdo, teve a menor média e os mais altos desvios padrões e coeficiente de variação, apontando para a heterogeneidade das respostas. Esse item pode fornecer duas interpretações distintas: a primeira, que os professores pouco ou nunca utilizam recursos didáticos e tecnológicos em sua aula; a segunda, que o professor não os utiliza de maneira adequada. Alguns autores que pesquisaram o perfil do bom professor concluiram que o bom docente, além de utilizar mais de uma técnica de ensino, tais como seminário, aula expositiva, trabalho em grupo, etc. (RODRIGUES; BARBOSA; BLOIS, 2006), utiliza adequadamente os recursos didáticos e tecnológicos (CUNHA, 2006). Desse modo, seria necessário aprofundar junto aos discentes avaliadores por que motivo esse item teve média inferior.

A variável que alcançou maior média e também maior homogeneidade de respostas, conforme verificado pelas medidas de dispersão foi o item 14, o qual questiona se o docente mantém comportamento cordial e respeitoso com os alunos. Esse é um dado positivo, uma vez que o relacionamento aluno-professor é importante para a composição do perfil do bom docente (PATRíCIO, 2005). 
Os coeficientes de variação oscilaram de 20,14 a 33,50\%, demonstrando que os alunos tendem a atribuir altas notas aos seus professores, com variação entre um quinto e um terço. Ou seja, nessa margem dos coeficientes de variação, as diferenças entre as médias dos docentes devem ser consideradas com a sua sutileza.

$\mathrm{Na}$ análise individual realizada por professor, foram calculados a média e o desvio padrão. Desse modo, a menor média obtida por um docente foi 3,3357 e a maior, 4,8026, sendo que apenas 20 dos 89 professores tiveram média nos 25 itens inferior a quatro pontos. 0 maior desvio padrão identificado foi 1,30698 e o menor, 0,33597.

Quando a análise foi desmembrada segundo os blocos de questões do instrumento (práticas pedagógicas, sistemas de avaliação e relações interpessoais), os resultados foram semelhantes. No primeiro bloco, sobre as práticas pedagógicas do professor, a média teve variação de 3,3317 a 4,8099 e o desvio padrão de 0,30139 a 1,41365. Em relação ao sistema de avaliação, a média variou de 3,2139 a 4,7629 e o desvio padrão de 0,34270 a 1,34110. No caso das relações interpessoais, a média variou de 3,4616 a 4,8262 e o desvio padrão de 0,29683 a 1,31446.

A tabela 2 apresenta a frequência das respostas dos alunos por item, em percentuais, excluídas as respostas inválidas. Os dados demonstram 0 alto índice percentual de alunos que atribuíram notas 5 e 4 aos seus professores. A mediana, ponto do meio da distribuição, foi 5 em 23 itens e 4 apenas nos itens 11 e 19. A moda, isto é, o valor mais frequente da escala, foi $5 \mathrm{em}$ todos os itens, o que é possivel perceber também pela interpretação dos dados apresentados na tabela 2 .

Tabela 2 - Frequência das respostas dos alunos por item no instrumento em percentuais.

\begin{tabular}{l|c|c|c|c|c}
\hline Item & 1 & 2 & 3 & 4 & 5 \\
\hline 1. Demonstra domínio do conteúdo. & 3,0 & 3,8 & 7,9 & 20,9 & 64,4 \\
\hline $\begin{array}{l}\text { 2. Demonstra clareza na apresentação } \\
\text { dos conteúdos ministrados. }\end{array}$ & 3,7 & 5,6 & 10,5 & 25,9 & 54,4 \\
\hline 3. Demonstra organização nos conteúdos ministrados. & 3,5 & 5,0 & 10,1 & 24,2 & 57,2 \\
\hline $\begin{array}{l}\text { 4. Ministra aulas interativas, incentivando } \\
\text { a participação dos alunos. }\end{array}$ & 5,5 & 6,1 & 12,5 & 24,0 & 52,0 \\
\hline 5. Demonstra ter preparado as aulas. & 3,8 & 4,4 & 9,6 & 22,3 & 59,9 \\
\hline $\begin{array}{l}\text { 6. Relaciona o conteúdo das aulas a } \\
\text { outras áreas do conhecimento. }\end{array}$ & 4,0 & 5,4 & 13,2 & 26,2 & 51,1 \\
\hline $\begin{array}{l}\text { 7. Relaciona o conteúdo das aulas } \\
\text { à realidade do mercado. }\end{array}$ & 4,0 & 4,7 & 11,7 & 24,4 & 55,1 \\
\hline $\begin{array}{l}\text { 8. Estabelece relação entre a teoria e a prática, } \\
\text { respeitadas as especificidades da disciplina. }\end{array}$ & 3,6 & 4,6 & 12,1 & 25,3 & 54,5 \\
\hline
\end{tabular}




\begin{tabular}{|c|c|c|c|c|c|}
\hline Item & 1 & 2 & 3 & 4 & 5 \\
\hline $\begin{array}{l}\text { 9. Apresenta o plano de ensino aos alunos } \\
\text { na primeira semana de aula. }\end{array}$ & 6,4 & 4,2 & 11,1 & 17,3 & 61,0 \\
\hline $\begin{array}{l}\text { 10. Cumpre as atividades programadas } \\
\text { no plano de ensino. }\end{array}$ & 4,0 & 3,9 & 12,0 & 22,5 & 57,6 \\
\hline $\begin{array}{l}\text { 11. Utiliza os recursos didáticos } \\
\text { (ex.: dinâmicas de grupo) e tecnológicos } \\
\text { (ex.: data show, retroprojetor) de maneira a } \\
\text { favorecer a compreensão do conteúdo. }\end{array}$ & 9,6 & 6,6 & 13,0 & 22,1 & 48,7 \\
\hline $\begin{array}{l}\text { 12. Incentiva a autonomia, a pesquisa } \\
\text { e o pensar critico dos alunos. }\end{array}$ & 4,8 & 4,9 & 12,6 & 24,5 & 53,3 \\
\hline $\begin{array}{l}\text { 13. Acompanha as atividades do aluno } \\
\text { (tarefas, trabalhos, projetos etc.) }\end{array}$ & 4,0 & 4,6 & 11,0 & 23,7 & 56,7 \\
\hline $\begin{array}{l}\text { 14. Mantém comportamento cordial } \\
\text { e respeitoso com os alunos. }\end{array}$ & 2,7 & 2,6 & 5,5 & 15,9 & 73,3 \\
\hline 15. Trata os alunos com critério e justiça. & 3,1 & 3,1 & 7,4 & 19,0 & 67,5 \\
\hline 16. Mantém a ordem e a disciplina da turma. & 3,5 & 4,6 & 10,7 & 24,7 & 56,4 \\
\hline 17. Está aberto às críticas e sugestões. & 5,2 & 4,4 & 10,9 & 21,7 & 57,8 \\
\hline 18. Tem disposição para esclarecer dúvidas. & 3,2 & 3,3 & 7,4 & 17,8 & 68,4 \\
\hline $\begin{array}{l}\text { 19. Estabelece estratégias de recuperação } \\
\text { de alunos de menor rendimento. }\end{array}$ & 5,8 & 5,1 & 15,8 & 25,1 & 48,1 \\
\hline $\begin{array}{l}\text { 20. Orienta o sistema de avaliação } \\
\text { (provas, trabalhos etc.) com clareza e precisão. }\end{array}$ & 3,2 & 4,1 & 9,3 & 22,7 & 60,7 \\
\hline $\begin{array}{l}\text { 21. Valoriza a reflexão e o pensar } \\
\text { crítico nos instrumentos de avaliação. }\end{array}$ & 3,3 & 4,2 & 12,8 & 25,3 & 54,5 \\
\hline $\begin{array}{l}\text { 22. Aplica avaliações coerentes } \\
\text { com o conteúdo ministrado. }\end{array}$ & 2,9 & 3,4 & 7,9 & 19,7 & 66,1 \\
\hline $\begin{array}{l}\text { 23. Corrige as avaliações respeitando } \\
\text { critérios previamente estabelecidos. }\end{array}$ & 2,8 & 3,1 & 8,4 & 19,8 & 65,9 \\
\hline $\begin{array}{l}\text { 24. Utiliza outros modos de avaliação que } \\
\text { não sejam única e exclusivamente provas. }\end{array}$ & 3,9 & 2,9 & 7,3 & 19,2 & 66,7 \\
\hline $\begin{array}{l}\text { 25. Faz análise e comentários acerca } \\
\text { dos resultados das avaliações. }\end{array}$ & 4,3 & 3,8 & 10,8 & 21,7 & 59,3 \\
\hline
\end{tabular}

Fonte: Pesquisa de campo (2006).

\section{Análise fatorial dos resultados}

A análise fatorial é uma técnica cujo objetivo é "condensar a informação contida em um número de variáveis originais em um conjunto menor de variáveis estatísticas (fatores) com uma perda mínima de informação" (HAIR et al., 2005, p. 32). 0 agrupamento dessas variáveis hipotéticas resultantes do conjunto original de variáveis recebe o nome de "fator". 0 fator é a causa comum que produz a correlação entre as variáveis empíricas (PASQUALI, 2003). 
Antes de realizar a análise fatorial do instrumento de avaliação, a amostra dos dados foi submetida a algumas medidas de adequação. 0 coeficiente Kaiser-Meyer-Olkin $(K M O=0,978)$ indicou alto grau de variância. Segundo Mingoti (2005), o KMO na faixa de 0,9 apresenta excelente adequação do modelo, sugerindo que o instrumento é apropriado para avaliar o desempenho do professor. Foi realizado também o teste Bartllet de esfericidade $(X 2=164027,3$; $p=0,000)$, o qual confirmou a adequação do instrumento. Este teste informa a probabilidade estatística de que haja correlações significantes entre as variáveis na matriz de correlação (HAIR et al., 2005). Por fim, o valor do determinante da matriz de correlação para as amostras foi de 2,04E-008, sugerindo, assim, que as variáveis estão fortemente intercorrelacionadas.

Depois de constatada a adequação do modelo, realizou-se a análise fatorial do instrumento de avaliação, que revelou a existência de dois fatores. 0 primeiro fator identificado inclui os itens 1 a 12 e abrange as práticas pedagógicas do professor em sala de aula, seus métodos e procedimentos didáticos. 0 segundo fator inclui os itens 13 a 25 e compreende os aspectos de relacionamento interpessoal do docente, bem como seus procedimentos de avaliação. Estiveram presentes em ambos os fatores o item 13, que questiona se o professor acompanha as atividades do aluno, e 0 item 16, o qual interroga se 0 docente mantém a ordem e a disciplina da turma. A tabela 3 apresenta a carga fatorial de cada item do instrumento.

A orientação presente nos manuais de estatística para a realização da análise fatorial é que a amostra tenha no mínimo 100 componentes. Dessa forma, na presente pesquisa, todos os itens superam a quantidade mínima de casos para 0 desenvolvimento desta técnica. Hair e outros (2005) explicam que, para haver significância prática das cargas fatoriais, é preciso que estas sejam maiores que 0,50. Para haver significância estatística, considerado o tamanho da amostra, a carga fatorial deve ser no mínimo 0,30. Desse modo, a tabela 3 evidencia que há no instrumento significância estatística e prática, exceto nos itens que pertencem simultaneamente aos dois fatores (itens 13 e 16), os quais têm significância estatística, mas não apresentam significância prática. Outro dado relevante é que os fatores explicam 59,596\% da variância. Todos esses dados conferem validade e fidedignidade ao instrumento, demonstrando a capacidade do instrumento de medir o desempenho dos professores.

Ressalta-se que, para interpretar os fatores, foi realizada a rotação fatorial oblíqua (Oblimin). A opção pela rotação oblíqua em detrimento da rotação ortogonal foi feita tendo em vista o alto índice de correlação entre os dois fatores $(r=0,777)$. 
Tabela 3 - Carga fatorial dos itens do instrumento.

\begin{tabular}{l|c|c}
\hline & \multicolumn{2}{|c}{ Fator } \\
\hline Item & 1 & 2 \\
\hline Item_02 &, 847 & \\
\hline Item_07 &, 844 & \\
\hline Item_05 &, 843 & \\
\hline Item_06 &, 836 & \\
\hline Item_03 &, 824 & \\
\hline Item_04 &, 788 & \\
\hline Item_01 &, 782 & \\
\hline Item_08 &, 766 & \\
\hline Item_11 &, 672 & \\
\hline Item_10 &, 626 & \\
\hline Item_09 &, 579 & \\
\hline Item_12 &, 554 & \\
\hline Item_15 & &, 896 \\
\hline Item_14 & &, 854 \\
\hline Item_23 & &, 830 \\
\hline Item_18 & &, 760 \\
\hline Item_22 & &, 759 \\
\hline Item_17 & &, 728 \\
\hline Item_24 & &, 727 \\
\hline Item_20 & &, 688 \\
\hline Item_19 & &, 640 \\
\hline Item_25 & &, 637 \\
\hline Item_21 & &, 616 \\
\hline Item_16 &, 336 &, 421 \\
\hline Item_13 &, 375 &, 418 \\
\hline I20_61 & & \\
\hline & & \\
\hline & & \\
\hline Ite & & \\
\hline It & & \\
\hline & & \\
\hline
\end{tabular}

Fonte: Pesquisa de campo (2006).

\section{Correlações}

A correlação é uma medida da relação linear entre duas variáveis quantitativas, quanto à direção e à intensidade (MOORE, 2005) e é medida pelo coeficiente de Pearson ( $r$ ). Nesta pesquisa, foram realizados testes de correlação de todas as variáveis quantitativas entre si, ou seja, idade do docente, tempo de serviço prestado na instituição, tempo de experiência na educação superior, quantidade de pontos de publicações científicas, segundo critérios estabelecidos pelo Plano de Carreira, quantidade total de publicações, quantidade de artigos publicados, quantidade de livros ou capitulos de livros publicados, escore geral do professor, média do docente no 
fator 1 (identificado na análise fatorial), média do docente no fator 2 (identificado na análise fatorial), média do professor em relação às práticas pedagógicas, quanto às relações interpessoais e em relação ao sistema de avaliação (conforme divisão de questões no próprio instrumento). Dessa forma, buscou-se atingir o segundo objetivo específico proposto para a pesquisa: relacionar as características dos professores valorizadas pelo Plano de Carreira (exceto a titulação) com o seu desempenho, segundo a avaliação dos alunos.

$\mathrm{Na}$ análise, verificou-se apenas a existência de correlações óbvias. Por exemplo: quanto maior a idade, mais tempo na educação superior $(r=0,507)$; quanto maior o tempo de experiência dos docentes na instituição, maior o tempo de experiência na educação superior $(r=0,249)$; quanto maior a quantidade de publicações, maior a quantidade de pontos de publicação $(r=0,928)$, conforme critérios estabelecidos pelo Plano de Carreira da instituição; quanto maior a média para o fator 1, maior 0 escore geral $(r=0,978)$; quanto maior a média nas práticas pedagógicas, maior a média para o fator $1(r=0,999)$.

0 coeficiente de Pearson revelou baixa correlação do escore geral dos docentes com as demais variáveis (idade, experiência na educação superior, tempo de serviço na instituição, pontos de publicação científica), indicando não haver interferência dessas variáveis na avaliação que os discentes fazem de seus professores. Este resultado demonstra que o Plano de Carreira da instituição apresenta critérios divergentes daqueles valorizados pelo alunado.

Apesar de não haver significância do ponto de vista estatístico, a relação entre a quantidade de livros ou capitulos de livros publicados (que, conforme o Plano de Carreira, também pode incluir revisões técnicas ou traduções) e o escore geral na avaliação dos docentes pelos alunos é digna de nota $(r=0,308)$. Do mesmo modo, a relação da quantidade de livros publicados e a média no fator $2(r=0,364)$, o qual se refere ao sistema de avaliação e às relações interpessoais do docente. É possível afirmar, embora com cautela, que os professores que publicam livros e artigos se destacam dos demais, ainda que não haja significância estatística para as relações entre as variáveis. Duas poderiam ser as dimensões dessa diferenciação em face dos demais: maior profundidade do conteúdo programático e maior capacidade de apresentar os temas aos leitores e, talvez por extensão, aos alunos.

Outro aspecto interessante é a alta correlação positiva entre a média do docente nas questões sobre o sistema de avaliação com a média nas relações interpessoais $(r=1,000)$. Esse resultado corrobora o fato de todas essas questões estarem agrupadas no fator 1, como identificado na análise fatorial dos resultados. Isso significa que, para os estudantes avaliadores, o docente que tem bom relacionamento interpessoal com os alunos é aquele que apresenta um bom sistema de avaliação. Esse 
vínculo entre o sistema de avaliação e as relações interpessoais poderia ser atribuído ao distanciamento do professor em relação a uma pedagogia monologada e a sua proximidade em face de uma perspectiva dialógica da educação, em que o educador orienta o sistema de avaliação, analisa e comenta os resultados, valoriza a reflexão e o pensar crítico, a qual é denominada por Paulo Freire (1987) "educação libertadora" ou "problematizadora". Essa concepção é o contrário da "educação bancária", na qual o aluno devolve na avaliação os conteúdos nele "depositados", inibindo a verdadeira reflexão, a criatividade e o conhecimento. 0 instrumento de avaliação do professor na instituição pesquisada indaga sobre aspectos da avaliação que exigem outra perspectiva do processo, com o professor colocando-se no lugar do aluno e buscando a recuperação da aprendizagem. Entretanto, aqui não se afirma, de modo algum, que os professores sigam a filosofia de Freire. Porém, é interessante considerar que saber colocar-se no lugar do discente é uma importante competência do campo das relações interpessoais.

Além disso, as questões acerca do sistema de avaliação estão pautadas nas características valorizadas pelo aluno, em relação aos procedimentos avaliativos, as quais foram destacadas por Berbel, Oliveira e Vasconcellos (2006): a orientação e 0 acompanhamento do aluno como processo do ensino; a interação entre o processo de ensino e a prática da avaliação; o nível de exigência nas avaliações, o uso de critérios de avaliação, a combinação de vários instrumentos de avaliação, a valorização do diálogo e o feedback.

\section{Teste $\mathrm{t}$ de student}

0 teste $t$ é definido como o "teste para avaliar a significância estatística da diferença entre duas médias amostrais para uma única variável dependente" (HAIR et al., 2005, p. 274). Foi realizado o teste $t$ para identificar a influência do gênero do docente sobre seu desempenho, conforme a opinião dos alunos. A tabela 4 apresenta os resultados do teste $t$.

Tabela 4 - Resultados do teste $t$.

\begin{tabular}{l|c|c|c}
\hline & $\mathrm{T}$ & Grau de liberdade & Sig. (2-tailed) \\
\hline ScoreGeral & $-1,812$ & 87 &, 073 \\
\hline MédiaFator1 & $-1,603$ & 87 &, 113 \\
\hline MédiaFator2 & $-2,052$ & 87 &, 043 \\
\hline MédiaPrat_Pedag & $-1,493$ & 87 &, 139 \\
\hline MédiaRelações_Interp & $-2,360$ & 87 &, 021 \\
\hline MédiaSist_Avaliação & $-2,360$ & 87 &, 021 \\
\hline
\end{tabular}

Fonte: Pesquisa de campo (2006). 
Os resultados demonstraram não haver significância estatística entre o gênero do docente e o escore geral $(t=1,812 ; p=0,073)$. Todavia, quando a mesma análise foi realizada considerando a média do docente por bloco de questões do instrumento, o resultado foi estatisticamente significativo para o bloco de relações interpessoais e também para o bloco de sistema de avaliação $(t=2,360 ; p=0,021)$, indicando que, nestes aspectos, os professores têm médias maiores que as professoras. Em relação às práticas pedagógicas, não houve diferença estatisticamente significativa $(p>0,05)$. Em relação à comparação dos resultados por gênero, o resultado deste estudo diverge das conclusões de Pounder (2007), segundo as quais, em geral, as professoras são mais bem avaliadas que os professores. Trata-se de um aspecto que merece ser estudado com maior profundidade em pesquisas futuras.

A tabela 5 apresenta os resultados descritivos que comparam os professores, segundo o gênero. Como o universo pesquisado é bastante restrito, as diferenças percentuais não apresentam relevância. Entretanto, a diferença entre os pontos de publicação no meio masculino $(m=87,12 ; s=276,939)$ e no meio feminino $(m=37,03$; $\mathrm{s}=62,533)$ merece destaque. Ainda assim, o dado deve ser examinado com cautela, tendo em vista a quantidade reduzida de publicadores.

Tabela 5 - Resultados descritivos comparativos entre professores, segundo o gênero.

\begin{tabular}{l|l|r|r}
\hline & & \multicolumn{1}{|c|}{ Masculino } & \multicolumn{1}{c}{ Feminino } \\
\hline \multirow{4}{*}{ Titulação } & Graduado & $19,2 \%$ & $13,5 \%$ \\
\cline { 2 - 4 } & Especialista & $28,8 \%$ & $27,0 \%$ \\
\cline { 2 - 4 } & Mestre & $48,1 \%$ & $54,1 \%$ \\
\cline { 2 - 4 } & Doutor & $3,8 \%$ & $5,4 \%$ \\
\hline \multirow{2}{*}{ Idade } & Média & 40,25 & 37,11 \\
\cline { 2 - 4 } & Desvio Padrão & 8,962 & 8,527 \\
\hline \multirow{2}{*}{ Experiência - educação superior } & Média & 5,7898 & 5,3038 \\
\cline { 2 - 4 } & Desvio Padrão & 3,83581 & 3,41209 \\
\hline \multirow{2}{*}{ Experiência - na IES } & Média & 2,3383 & 1,9968 \\
\cline { 2 - 4 } & Desvio Padrão & 1,30144 & 1,24501 \\
\hline \multirow{2}{*}{ Pontos publicação } & Média & 87,12 & 37,03 \\
\cline { 2 - 4 } & Desvio Padrão & 276,939 & 62,533 \\
\hline
\end{tabular}

Fonte: Pesquisa de campo (2006).

\section{Análise de variância (ANOVA)}

A análise de variância (ANOVA) é uma técnica estatística utilizada para verificar se as amostras de dois ou mais grupos são oriundos de populações com médias iguais. É um procedimento univariado por ser utilizado com a finalidade de avaliar diferenças de grupos considerando apenas uma variável dependente métrica (HAIR 
et al., 2005). A análise de variância "testa se várias populações têm a mesma média, comparando o afastamento entre as médias amostrais com a variação existente dentro das amostras" (MOORE, 2005, p. 518). No presente estudo, a ANOVA foi calculada para identificar a significância da relação entre a titulação do professor e os escores por eles obtidos na avaliação realizada pelos alunos, de modo a atingir o segundo objetivo proposto para a pesquisa, isto é, relacionar as características dos professores valorizadas pelo Plano de Carreira (especialmente a titulação) com o seu desempenho na avaliação dos alunos. Após a realização dos testes principais, foi realizado o método da diferença honestamente significante (HSD) de Tukey. A finalidade deste teste, bem como de outros testes post hoc é identificar a existência de diferenças significantes nas comparações entre grupos, ou seja, estes métodos testam cada combinação de grupos.

Como a quantidade de doutores (quatro) na instituição à época da pesquisa era pequena, a análise de variância foi realizada duas vezes. Na primeira, considerando a distribuição dos professores por titulação na instituição. Na segunda, os doutores foram excluídos da amostra a fim de verificar novamente o efeito da titulação sobre a avaliação dos alunos. Os dados obtidos demonstram que não há relação estatisticamente significativa entre a titulação e os escores obtidos pelos professores. Contudo, uma limitação da pesquisa refere-se ao tamanho da amostra e ao fato de o estudo envolver apenas uma instituição. Apesar desta limitação, os resultados encontrados corroboram as conclusões encontradas por outros pesquisadores, mesmo que essas pesquisas tenham sido realizadas em outros níveis de ensino (RIVKIN; HANUSHEK; KAIN, 2005; KANE; ROCKOFF; STAIGER, 2006; CRONINGER et al., 2007).

A comparação entre as duas análises de variâncias realizadas revelou que, ao excluir os quatro doutores da análise, o valor de $p$ aumenta em todas as variáveis dependentes pesquisadas, ou seja, piora ainda mais o nivel de significância. Este dado pode sugerir que os doutores da amostra tiveram uma avaliação positiva dos seus alunos, apesar de a titulação não ter influência estatisticamente significante sobre os resultados da avaliação.

Apesar de a ANOVA nos permitir rejeitar a hipótese nula de que as médias de grupos são todas iguais, elas não apontam precisamente onde estão as diferenças significantes quando há mais de dois grupos. Daí a necessidade de se utilizar os testes post hoc, pois eles servem para aprofundar as diferenças específicas de médias entre os grupos (HAIR et al., 2005). A necessidade de fazer testes post hoc existe caso seja identificada na análise de variância alguma diferença significante entre os grupos. Mesmo não sendo o caso da presente pesquisa, pois a própria análise de variância revelou a ausência de diferença estatisticamente significante entre os diferentes grupos, foi desenvolvido o teste post hoc da diferença honesta- 
mente significante (HSD), de Tukey, o qual é utilizado para identificar quais comparações entre grupos apresentam diferenças significantes (HAIR et al., 2005) e, como era esperado, foi confirmada a ausência de diferença estatisticamente significante entre os diferentes escores.

Ao retirar os doutores da análise, o resultado da pesquisa não foi modificado, ou seja, a ausência de diferenças significantes entre os grupos de diferentes titulações permaneceu. Da mesma forma, as amostras homogêneas resultantes do teste de Tukey confirmaram a ausência de significância estatística entre os grupos.

\section{Regressão múltipla}

A regressão múltipla é considerada "uma técnica estatística geral usada para analisar a relação entre uma única variável dependente e diversas variáveis independentes"1. Hair e colaboradores (2005) explicam que, para realizar a análise de regressão múltipla, dois requisitos devem ser observados: todos os dados devem ser métricos ou transformados em dados métricos e devem ser definidas as variáveis dependentes e independentes. Na presente pesquisa, foi assumida como variável dependente o desempenho dos professores, segundo as avaliações de seus alunos, e, como variáveis independentes, as características docentes valorizadas pelo Plano de Carreira: tempo de experiência na educação superior, tempo de trabalho na instituição, pontos de publicação científica. Além dessas, foi incluida também a variável idade.

Os valores de beta, "que permitem a comparação entre coeficientes e seus poderes relativos de explicação da variável dependente" (HAIR et al., 2005, p. 132), indicam que nenhuma das variáveis independentes influencia o escore geral dado pelos alunos aos professores. A tabela 6 patenteia que nenhuma das variáveis independentes é capaz de explicar a variável dependente da pesquisa $(p>0,05)$.

Tabela 6 - Resultados da regressão múltipla.

\begin{tabular}{l|c|c}
\hline & Coeficiente Beta & Sign. \\
\hline (Constante) & &, 000 \\
\hline Idade &, 029 &, 820 \\
\hline Pontos publicação &, 116 &, 286 \\
\hline Experiência educação superior &, 124 &, 331 \\
\hline Tempo de trabalho na instituição &,- 102 &, 362 \\
\hline
\end{tabular}

Fonte: Pesquisa de campo (2006). 
Essa conclusão é divergente dos resultados encontrados pela pesquisa de McPherson (2006), que identificou que docentes com mais de 11 semestres de experiência tiveram pontuação mais alta que os demais na avaliação realizada pelos alunos. Além disso, em sua pesquisa, docentes com experiência entre cinco e dez semestres tiveram pontuação maior que os colegas que tinham menos de cinco semestres de prática docente. Já na pesquisa bibliográfica realizada por Pounder (2007), a influência tanto da idade como do tempo de experiência dos professores na avaliação pelos alunos são divergentes na literatura.

A respeito da variável tempo de experiência, a literatura apresenta dados que relacionam essa variável com o desempenho dos alunos. As pesquisas de Mello e Souza (2005), Albernaz, Ferreira e Franco (2002), Goldhaber e Brewer (1996) e Casassus (2002) identificaram ausência de significância e até mesmo relação negativa entre a experiência docente e o rendimento estudantil. 0 presente estudo não identificou relação significante entre o tempo de experiência dos professores e o seu próprio desempenho em sala de aula. Ou seja, na perspectiva dos alunos, o professor bem avaliado não necessariamente é o professor com maior ou menor tempo de experiência em sala de aula.

$\mathrm{Na}$ análise de regressão múltipla, foi calculado, ainda, o coeficiente de determinação (R2), o qual é definido como a "medida da proporção da variância da variável dependente em torno de sua média que é explicada pelas variáveis dependentes" (HAIR et al., 2005, p. 132). Na análise em questão, o coeficiente de determinação $(R 2)$ foi 0,038 , sugerindo que apenas $3,8 \%$ das variáveis independentes explicam as variações das avaliações do alunado.

\section{Conclusões}

A presente pesquisa buscou verificar se os critérios de progressão no Plano de Carreira de uma instituição são os mesmos que fazem de um docente um bom professor na perspectiva dos alunos. Inicialmente, verificou-se o desempenho dos professores da instituição pesquisada segundo a avaliação de seus alunos. Os resultados apresentaram um alto valor relativo das médias em cada item do instrumento de avaliação, que devem ser encarados com cautela, inclusive tendo em vista o baixo desvio padrão das respostas dos alunos, indicando homogeneidade de respostas. Pelo menos duas interpretações são possiveis para este resultado. Pela primeira, pode-se atribuir a variação à seleção dos docentes pela instituição, a qual envolve análise curricular, entrevista e micro-aula. Na segunda perspectiva, pode-se atribuir a homogeneidade de respostas à relação passiva dos alunos frente ao docente, visto que o sujeito frequentemente avaliado tornou-se o avaliador.

Após verificar o desempenho dos docentes, procurou-se relacionar as características dos professores valorizadas pelo Plano de Carreira, isto é, titulação, tempo de experiência docente e publicações, com seu desempenho na avaliação dos dis- 
centes. Para tanto, foram desenvolvidas diversas análises estatísticas. 0 quadro 1 sintetiza os objetivos e os resultados de cada técnica estatística empregada para alcançar o objetivo desta pesquisa.

\begin{tabular}{|c|c|c|}
\hline $\begin{array}{l}\text { Técnica } \\
\text { Estatística }\end{array}$ & Objetivo & Resultados \\
\hline $\begin{array}{l}\text { Análise } \\
\text { Fatorial }\end{array}$ & $\begin{array}{l}\text { - Medir a adequação do instru- } \\
\text { mento; } \\
\text { - Condensar a informação do ins- } \\
\text { trumento em um número redu- } \\
\text { zido de variáveis (fatores). }\end{array}$ & $\begin{array}{l}\text { - Excelente adequação do instrumento; } \\
\text { - Identificação de dois fatores: o pri- } \\
\text { meiro abrangendo as práticas peda- } \\
\text { gógicas do professor em sala de aula, } \\
\text { seus métodos e procedimentos didá- } \\
\text { ticos; o segundo, aspectos sobre o re- } \\
\text { lacionamento interpessoal do docen- } \\
\text { te, bem como seus procedimentos de } \\
\text { avaliação do processo ensino-apren- } \\
\text { dizagem. }\end{array}$ \\
\hline $\begin{array}{l}\text { Correlações } \\
\text { (Pearson) }\end{array}$ & $\begin{array}{l}\text { - Relacionar algumas caracterís- } \\
\text { ticas dos professores (idade, ex- } \\
\text { periência na educação superior, } \\
\text { tempo de serviço na instituição, } \\
\text { pontos de publicação científica) } \\
\text { com seu desempenho na avalia- } \\
\text { ção dos alunos. }\end{array}$ & $\begin{array}{l}\text { - Baixa correlação do escore geral dos } \\
\text { docentes com as demais variáveis (ida- } \\
\text { de, experiência na educação superior, } \\
\text { tempo de serviço na instituição, pon- } \\
\text { tos de publicação científica); } \\
\text { - Apenas correlações óbvias; } \\
\text { - Alta correlação positiva entre a mé- } \\
\text { dia do docente nas questões sobre o } \\
\text { sistema de avaliação e a média nas } \\
\text { questões sobre relações interpessoais. }\end{array}$ \\
\hline $\begin{array}{l}\text { Teste } t \text { de } \\
\text { student }\end{array}$ & $\begin{array}{l}\text { - Identificar a influência do gêne- } \\
\text { ro do docente sobre seu desem- } \\
\text { penho. }\end{array}$ & $\begin{array}{l}\text { - Ausência de significância estatística } \\
\text { entre o escore geral e o gênero do } \\
\text { docente; } \\
\text { - Resultado estatisticamente significa- } \\
\text { tivo para questões sobre relações in- } \\
\text { terpessoais e sistemas de avaliação } \\
\text { (professores têm escore superior que } \\
\text { professoras). }\end{array}$ \\
\hline $\begin{array}{l}\text { Análise de } \\
\text { Variância } \\
\text { (ANOVA) }\end{array}$ & $\begin{array}{l}\text { - Relacionar a titulação do pro- } \\
\text { fessor com seu desempenho na } \\
\text { avaliação dos alunos. }\end{array}$ & $\begin{array}{l}\text { - Ausência de relação estatisticamente } \\
\text { significativa entre a titulação e os es- } \\
\text { cores obtidos pelos professores. }\end{array}$ \\
\hline $\begin{array}{l}\text { Regressão } \\
\text { Múltipla }\end{array}$ & $\begin{array}{l}\text { - Relacionar algumas caracterís- } \\
\text { ticas dos professores (idade, ex- } \\
\text { periência na educação superior, } \\
\text { tempo de serviço na instituição, } \\
\text { pontos de publicação científica) } \\
\text { com seu desempenho na avalia- } \\
\text { ção dos alunos. }\end{array}$ & $\begin{array}{l}\text { - Nenhuma das variáveis analisadas é } \\
\text { capaz de explicar o escore geral atri- } \\
\text { buído aos professores pelos seus alu- } \\
\text { nos. }\end{array}$ \\
\hline
\end{tabular}

Quadro 1 - Síntese dos objetivos e resultados das técnicas estatísticas empregadas na pesquisa.

Fonte: Pesquisa de campo (2006). 
0 quadro 1 revela que todas as análises empregadas convergiram para a constatação de que, na instituição pesquisada, não houve relação estatisticamente significante entre a avaliação dos docentes e as variáveis valorizadas pelo Plano de Carreira. É relevante ressaltar, no entanto, que esta pesquisa exploratória é insuficiente para contradizer a literatura, embora constitua um fundamento para discussão dos resultados das demais pesquisas e possa servir de base a outras investigações.

Os resultados desta pesquisa não são generalizáveis, a não ser na perspectiva naturalistica, com todas as respectivas precauções. 0 principal objetivo da instituição estudada é formar profissionais nas diversas áreas, capazes de operar o seu corpus de conhecimento. 0 Plano de Carreira valoriza um professor com determinadas características e os incentiva nessa direção, mas o julgamento dos alunos segue outros critérios e outros caminhos. Exceto, de maneira tênue, no que se refere às publicações, nenhuma das análises estatísticas mostrou impactos significativos das características examinadas. Do ponto de vista estritamente econômico, não faria sentido premiar os docentes a não ser pelas suas capacidades pertinentes, que, de fato, os levem a um melhor desempenho. Todavia, aqui se reconhece uma limitação: a avaliação dos alunos constitui apenas uma das perspectivas da avaliação, uma nesga da realidade, pois eles são apenas um dos grupos de atores que devem ser consultados. Para haver um julgamento mais amplo e profundo a respeito das características dos professores, a avaliação deve ser realizada por múltiplos agentes (CALÇAS; DOMINGOS, 2006; POUNDER, 2007; VIANNA, 2004).

A sociedade e o Estado, se assim optam, podem requerer qualidades diferentes nos seus profissionais formados pelas instituições de ensino superior. 0 que é bom ou melhor para o aluno, no calor do processo de aprendizagem, ainda desenvolvendo juízos sobre o que é ou não uma boa educação superior, um bom ou mau docente, pode não ser necessariamente o melhor para o aluno formado e para a sociedade de que ele faz parte. Aqui ainda se enfrenta um complexo problema: o aluno é o aprendente e as filosofias e teorias avançadas da educação, como as de Rogers $(1973)$ e Freire $(1987,1996)$, entre outros, situam o aluno como centro do processo educativo. Coerentemente, o Exame Nacional de Desempenho dos Estudantes (ENADE), parte do sistema de avaliação construído pelo Estado de Direito em nome da sociedade, verifica o que o aluno aprendeu e a diferença entre o que ele já "sabia" ao entrar no curso de graduação e o que ele passou a "saber", prestes a dele sair. Esse não seria também um forte argumento para estimular e premiar os professores mais capazes de conduzir aos resultados esperados pela avaliação oficial?

Os resultados desta pesquisa suscitam mais indagações que respostas, uma vez que, além de contrariarem o senso comum, divergem da maior parte da literatura e da legislação e normas nacionais a respeito dos professores mais bem sucedidos, bem como da sua premiação. Não se poderia defender que um país dispensasse 
doutores ou mestres ou, ainda, a sua produção cientifica, para alcançar melhor nível de qualidade da educação superior. Ao contrário, os critérios internacionalmente empregados valorizam a escolaridade mais longa, que representa supostamente maior tempo de contato com a área do conhecimento; maiores leitura, aprofundamento e especialização. Igualmente, eles valorizam obras julgadas por pares em conselhos editoriais, geralmente cientistas de maior renome, e publicadas sob diversas formas, indicando contribuições novas para o campo do conhecimento. A internacionalização da produção científica é outro critério que indica maior valorização do conhecimento e o situar-se nas frentes de desvendamento da ciência.

Ao enunciar justificativas para esses critérios, parece ficar claro que eles estão voltados para a produção de conhecimentos, para o aprofundamento especializado e para a formação de redes que impulsionam a vanguarda das ciências. Então, seriam eles apropriados a professores que devem introduzir os alunos ao conhecimento e à atualidade científica, como defendem Demo (1998), Freire (1996) e Cunha (1996)? As capacidades avaliadas pelo instrumento de coleta de dados desta pesquisa estão mais voltadas para o "pedagogo", ou melhor, "andragogo", isto é, aquele que, entre outras capacidades, conduz o discente adulto a dominar e aplicar conceitos, noções e teorias.

0 relacionamento interpessoal logo se destaca, sugerindo o que teorias da aprendizagem e certas visões da pós-modernidade explicam: aprender não é apenas um processo racional, mas envolve emoções, calor humano e processos de incentivação e motivação. A perspectiva psicanalítica explica o relacionamento interpessoal entre aluno e professor, defendendo que, como qualquer outro, essa relação é fundamentada no amor e no ódio, os dois afetos da estrutura psíquica. Assim, a forma como o aluno vê o professor pode favorecer ou não a aprendizagem (GIL, 2008). Já na perspectiva humanista, segundo a visão de Rogers (1973, p. 105), a aprendizagem

não se baseia nas habilidades de ensinar de um líder, no seu conhecimento erudito do campo, no planejamento do currículo, no uso de subsídios áudio-visuais, na programação do computador utilizado, nas palestras e aulas expositivas, na abundância de livros, embora tudo isso possa, uma vez ou outra, ser empregado como recurso importante. Não, a facilitação da aprendizagem significativa baseiase em certas qualidades de comportamento que ocorrem no relacionamento pessoal entre o facilitador e o aprendiz.

Sendo o processo ensino-aprendizagem envolvido por sentimentos e emoções, seriam necessários mestres, doutores e produtores de ciência que agem nos termos da racionalidade? Ou o ensino-aprendizagem dispensaria uma possivel sofisticação, em favor de outras características do docente? Ou, ainda, os programas de pósgraduação deveriam preparar não só o cientista, mas também o professor e nele 
cultivar características valorizadas pelos alunos, caso se opte pela associação entre ensino e pesquisa? $\mathrm{Ou}$, além disso, o processo de ensino-aprendizagem se faz, nas instituições de ensino superior, de modo errôneo? Deveria ele se efetuar pela descoberta e pela redescoberta segundo os critérios da pesquisa e a linha educacional construtivista? Se for esse o caso, os programas de pós-graduação estão voltados para desenvolver o professor nessa direção? Pelo fato de aprenderem a pesquisar, a avançar sobre fronteiras novas do conhecimento, o mestre e o doutor serão capazes por si sós de transferir essas capacidades para o processo de ensino-aprendizagem na sala de aula, com os seus alunos?

A própria Constituição Federal brasileira prescreve a associação entre ensino e pesquisa, com apoio na expectativa de que o melhor ensino é realizado pelos que mais pesquisam. Esse matrimônio teve a sua origem na Alemanha (MEISTER, 2003), não apenas com a união entre ensino e pesquisa, mas também com a aplicação da pesquisa a terrenos práticos, de significação econômica. Os Estados Unidos, com fundamento nessa experiência, aplicaram esse princípio da associação ensino-pesquisa aos seus programas de pós-graduação, já que o elevado número de alunos de programas de graduação não propiciava condições favoráveis para tanto (CLARK, 1995).

Seria então o pesquisador o melhor professor? Seria o melhor professor também o melhor pesquisador? 0 melhor lugar para a pesquisa seria aquele onde se ensina? $\mathrm{E}$ o melhor lugar para o ensino seria aquele onde se pesquisa? Existe um amplo e sólido conjunto de razões aceitas para que esse matrimônio não termine em divórcio. Entretanto, apesar das pressões da sociedade e da economia do conhecimento, nem todos os sistemas de educação superior associam ensino e pesquisa, pelo menos ao nível dos programas de graduação. Pode-se mencionar a França, a Espanha e a Inglaterra. Estariam eles defasados e sob risco de obsolescência ou perda de posição?

Assim, respondendo às questões propostas para este trabalho, constatou-se que o Plano de Carreira, utilizando critérios comuns a numerosos outros planos no País, não premia necessariamente os melhores professores, mas aqueles que têm maior quantidade de publicações científicas, mais tempo de experiência como docentes e são bem titulados. Concluiu-se que, na instituição pesquisada, não há relação entre a avaliação que 0 aluno faz de um professor com tais caracteristicas (idade, tempo de experiência na educação superior, tempo de experiência na instituição, titulação e publicação científica). Pelo contrário, essas variáveis explicam apenas 3,8\% das variações das avaliações do corpo discente.

Desse modo, sugere-se que os sistemas de promoção e progressão na carreira docente sejam fundamentados no mérito do professor, e não apenas em suas qualificações. Para isso, é preciso que as políticas educacionais brasileiras passem a ter base empírica, considerando o rendimento dos alunos e o desempenho dos profes- 
sores, tendo em vista que a qualidade da docência é, dentre as variáveis intraescolares, a mais influente sobre o rendimento dos alunos (NAVARRO, 2002; WRIGHT; HORN; SANDERS, 1997).

Um ponto é, porém, fundamental: a pesquisa não tem respostas simplistas para problemas complexos. Não se pode indiscriminadamente considerar que mestres e doutores, publicadores, com maior tempo de experiência, não fazem diferença. Contudo, a pesquisa acende luzes de dúvidas que não podem ser ignoradas.

\section{Referências}

ALBERNAZ, A.; FERREIRA, F. H. G.; FRANCO, C. Qualidade e equidade no ensino fundamental brasileiro. Pesquisa e Planejamento Econômico, Rio de Janeiro, v. 32, n. 3, p. 453-476, dez. 2002.

BERBEL, N. A. N.; OLIVEIRA, C. C.; VASCONCELLOS, M. M. M. Práticas avaliativas consideradas positivas por alunos do ensino superior: aspectos didáticopedagógicos. Estudos em Avaliação Educacional, São Paulo, v. 17, n. 35, p. 135158, set./dez. 2006.

BOURDIEU, P.; PASSERON, J. C. A reprodução: elementos para uma teoria do sistema de ensino. Tradução de Reynaldo Bairão. Rio de Janeiro: Livraria Francisco Alves, 1975.

CALÇAS, A. Q. P.; DOMINGOS, N. A. M. A avaliação do docente na perspectiva do alunado. Avaliação, Campinas, v. 11, n. 4, p. 99-108, dez. 2006.

CASASSUS, J. A escola e a desigualdade. Tradução de Lia Zatz. Brasília, DF: Plano, 2002.

CLARK, B. R. Places of inquiry: research and advanced education in modern universities. Berkeley, CA: University of California, 1995.

CRONINGER, R. G. et al. Teacher qualifications and early learning: effects of certification, degree, and experience on first-grade student achievement.

Economics of Education Review, Amsterdam, v. 26, n. 3, p. 312-324, Jun. 2007.

CUNHA, M. I. O bom professor e sua prática. 18. ed. Campinas: Papirus, 2006. . Relação ensino e pesquisa. In: VEIGA, I. P. A.V. (Org.). Didática: o ensino e suas relações. 7. ed. Campinas: Papirus, 1996.

DEMO, P. Educar pela pesquisa. 3. ed. Campinas: Autores Associados, 1998. 
FIGLIO, D. N.; KENNY, L. W. Individual teacher incentives and student performance. Journal of Public Economic, Amsterdam, v. 91, n. 5-6, p. 901-914, Jun. 2007.

FREIRE, P. Pedagogia da autonomia: saberes necessários à prática educativa. 27. ed. São Paulo: Paz e Terra, 1996.

. Pedagogia do oprimido. 25. ed. Rio de Janeiro: Paz e Terra, 1987.

GIL, A. C. Didática do ensino superior. São Paulo: Atlas, 2008.

GOLDHABER, D. D.; BREWER, D. J. Evaluating the effect of teacher degree level on educational performance. In: FOWLER, J. W. (Ed.). Developments in school finance. Washington, DC: National Center for Education Statistics, 1996.

GOMES, C. A. A educação em novas perspectivas sociológicas. 4. ed. São Paulo: EPU, 2005.

HAIR JR., J. F. et al. Análise multivariada de dados. 5. ed. Porto Alegre: Bookman, 2005.

HANUSHEK, E. A. et al. The market for teacher quality. National Bureau of Economic Research, Cambridge, MA, 2005. (NBER working paperseries; $n$. 11154). Disponivel em: <http://www.nber.org/papers/w11154.pdf>. Acesso em: 30 abr. 2007.

HANUSHEK, E. A. Teacher compensation. In: PETERSON, P. E. (Ed.). Reforming education in Florida. Palo Alto, CA: Hoover Institution Press, 2006.

HANUSHEK, E. A.; RIVKIN, S. G. Teacher quality. In: HANUSHEK, E.; WELCH, F. (Ed.). Handbook of the economics of education. Amsterdam: Elsevier Science \& Technology Books, 2006. v. 2.

HOFFMANN, F.; OREOPOULOS, P. Professor qualities and student achievement. Cambridge, MA: 2006. (NBER working paper series; n. 12596). Disponivel em: <http://www.nber.org/papers/w12596.pdf>. Acesso em: 6 dez. 2007.

KANE, T. J.; ROCKOFF, J. E.; STAIGER, D. 0. What does certification tell us about teacher effectiveness?: evidence from New York City. Cambridge, MA: 2006. (NBER working paper series; n. 12155). Disponivel em: <http:// www.nber.org/papers/w12155.pdf>. Acesso em: 17 nov. 2006.

McPHERSON, M. A. Determinants of how students evaluate teachers. Journal of Economic Education, Bloomington, Indiana, v. 37, n. 1, p. 3-20, Winter 2006. 
MEISTER, R. J. A universidade do século XXI: uma perspectiva americana. In: MEYER JR., V.; MURPHY, J. P. (Org.). Dinossauros, gazelas e tigres: novas abordagens da administração universitária: um diálogo Brasil e EUA. 2. ed. Florianópolis: Insular, 2003.

MELLO E SOUZA, A. Determinantes da aprendizagem em escolas municipais. Ensaio, Rio de Janeiro, v. 13, n. 49, p. 413-434, out./dez. 2005.

MINGOTI, S. A. Análise de dados através de métodos de estatistica multivariada: uma abordagem aplicada. Belo Horizonte: UFMG, 2005.

MOORE, D. S. A estatística básica e sua prática. 3. ed. Rio de Janeiro: LTC, 2005.

NAVARRO, J. C.. El docente latinoamericano: carrera, incentivos y desempeño. In: . (Ed.). ¿Quiénes son los maestros?: carreras e incentivos docentes en América Latina. Washington, DC: Banco Interamericano de Desarrollo, 2002.

OLIVEIRA, J.; FARRELL, J. P. Teacher costs and teacher effectiveness. In: FARRELL, Joseph P.; OLIVEIRA, J. B. (Org.). Teacher in developing countries: improving effectiveness and managing costs. Washington, DC: The World Bank, 1993.

PASQUALI, L. Psicometria: teoria dos testes na psicologia e na educação. 2. ed. Petrópolis: Vozes, 2003.

PATRÍCIO, P. São deuses os professores?: o segredo dos professores de sucesso. Campinas: Papirus, 2005.

POUNDER, J. S. Is student evaluation of teaching worthwhile? An analytical framework for answering the question. Quality Assurance in Education, Bingley, UK, v. 15, n. 2, p. 178-191, 2007.

RIVKIN, S. G.; HANUSHEK, E. A.; KAIN, J. F. Teachers, schools, and academic achievement. Econometrica, Hoboken, NJ, v. 73, n. 2, p. 417-458, Mar. 2005.

RODRIGUES, F. P. M.; BARBOSA, C. I. V.; BLOIS, M. D. 0 processo de avaliação institucional como multiplicador de iniciativas para o aperfeiçoamento docente: $1^{\text {a }}$ parte. Avaliação, Campinas, v. 11, n. 2, p. 151-166, jun. 2006.

ROGERS, C. R. Liberdade para aprender. 2. ed. Belo Horizonte: Interlivros, 1973.

SCHACTER, J.; THUM, Y. M. Paying for high- and low-quality teaching. Economics of Education Review, Amsterdam „, v. 23, n. 4, p. 311-430, Aug. 2004. 
SOARES, J. F. 0 efeito da escola no desempenho cognitivo de seus alunos. In: MELLO E SOUZA, A. (Org.). Dimensões da avaliação educacional. Petrópolis: Vozes, 2005.

STRONGE, J. H.; TUCKER, P. D.; HINDMAN, J. L. Handbook for qualities of effective teachers. Virginia: ASCD, 2004.

TACHIZAWA, T.; ANDRADE, R. 0. B. de. Gestão de instituições de ensino. 4. ed. Rio de Janeiro: FGV, 2006.

VEGAS, E.; UMANSKY, I. Improving teaching and learning through effective incentives. In: VEGAS, E. (Ed.). Incentives to improve teaching: lessons from Latin America. Washington, DC: The World Bank, 2005a.

Mejorar la enseñanza y el aprendizaje por medio de incentivos: ¿qué lecciones nos entregan las reformas educativas de América Latina?. Washington, DC: Banco Mundial, $2005 b$.

VIANNA, H. M. Avaliação de cursos pelos alunos: considerações. Estudos em Avaliação Educacional, São Paulo, n. 29, p. 137-147, jan./jun. 2004.

WAYNE, A. J.; YOUNGS, P. Teacher characteristics and student achievement gains: a review. Review of Educational Research, Thousand Oaks, CA, v. 73, n. 1, p. 89-122, Spring 2003.

WRIGHT, S. P.; HORN, S. P.; SANDERS, W. L. Teacher and classroom context effects on student achievement: implications for teacher evaluation. Journal of Personnel Evaluation in Education, Boston, v. 11, n. 1, p. 57-67, 1997.

ZABALZA, M. A. 0 ensino universitário: seu cenário e seus protagonistas. Porto Alegre: Artmed, 2004.

Recebido em: 12/03/2009

Aceito para publicação em: 04/04/2009 